\title{
Strategic and Organizational Evolutions of High-Tech SME on Global Market
}

\author{
Oualid Abidi, Zhan Su, Muhammad Mohiuddin \\ Laval University, Quebec, Canadian
}

\begin{abstract}
The "OLI paradigm” of Dunning (1977) claims that firm internationalization is addressed toward the exploitation of home-based specific advantages. However, evidence shows that SMEs are increasingly internationalizing their activities in order to enrich their resource pool. In this regard, a reinterpretation of the OLI paradigm came out with a new perspective suggesting that "foreign direct investment" (FDI) is increasingly oriented toward asset augmentation. Correspondingly, the purpose of this theoretical paper is to suggest a set of principles that could inform on how global small and medium-sized enterprises grow in the international marketplace when investing abroad.
\end{abstract}

Keywords: SME, OLI, knowledge, exploitation, exploration

\section{Introduction}

From a business viewpoint, globalization refers to "the tendency to configure their activities on a worldwide basis and to co-ordinate and integrate their strategies and their operations across national boundaries" (Stonehouse, Campbell, Hamill, \& Purdie, 2007, p. 5). Today, global firms do not fear the engagement in foreign markets. They address the world as a unique integrated platform. This strategy of linking global markets is a convenient alternative for firms who lack resources such as small and medium-sized firms (SMEs).

Because of the increasing complexity of the international marketplace and the growing sophistication of consumer preferences, global firms realized the need for a more flexible and responsive strategy with respect to the host country environment. Thus, they start applying the transnational strategy, which consists of bonding global coordination and local responsiveness, within an overarching learning perspective, in order to achieve higher competitiveness. In transnational strategy, worldwide knowledge is therefore emphasized as an asset (Stonehouse et al., 2007).

The previous statement is in line with the "ownership-localization-internalization paradigm” (OLI paradigm), which stresses that firms could invest abroad in order to develop new capabilities (Dunning, 2000). In addition to sales concerns, an internationalizing SME can target internal growth when investing in a host country. In regards to this statement, we argue for a potential strategic and organizational evolution that can occur within the FDI stage. Mathews (2006) argues that to upgrade their pool of resources, global firms experiment strategic and organizational innovations on the global market. This statement is likely to enlarge the Uppsala stage framework,

Oualid Abidi, Ph.D. candidate, Laval University.

Zhan Su, full professor and director of Stehpen-A.-Jarislowsky Chair in international business at Laval University.

Muhammad Mohiuddin, Ph.D. candidate, Laval University. 
which does not discuss how global SMEs grow, as they foster their commitment to the international marketplace. This model copes only with the sales growth imperative. From this concept, we propose to introduce a knowledge creation perspective in the last stage of the Uppsala model, which corresponds to FDI.

In fact, knowledge is created through two learning approaches, i.e., exploitation and exploration (Bierly III, Damanpour, \& Santoro, 2009). Organizations are making ongoing trade-offs between exploitation and exploration (Kane \& Alavi, 2007). These approaches differ regarding the strategic goals and the related organizational practices (He \& Wong, 2004). Our purpose is to explore how global SMEs are balancing exploitation and exploration on strategic and organizational levels in order to enhance knowledge-creation when investing abroad. Actually, there is a need to probe into SME globalization regarding the dynamics of knowledge creation (Chen \& Martin, 2001). As a matter of fact, a literature gap remains regarding SME globalization, despite the increase of their relative share in FDI during the last two decades (Gassmann \& Keupp, 2007).

This paper is organized as follows: In the first section, we discuss the new configuration of the OLI paradigm. In doing so, we underline the interest of global SMEs in multi-domestic knowledge creation and present the ambidexterity assumption (presence of two underlying processes in knowledge-creation). The second section will shed light on our propositions regarding the strategic as well as the organizational trends in knowledge creation among global SMEs. The final section will highlight our theoretical contributions.

\section{Related Work}

The conventional argument advanced by the OLI framework regarding the impulse of internationalization is based on the capacity of the firm to exploit its home-based advantages on other markets. Afterwards, scholars started considering that internationalization can be instigated by the search for new resources by using JVs and partnerships. The adherents to the OLI eclectic framework have attempted to steer it in different directions in order to accommodate some developments such as the proliferation of mergers, acquisitions, alliances and JVs. Indeed, the classic perspective of the OLI paradigm overlooks the cases of firms expanding abroad to gain access to strategic resources and assets. It was addressed to large multinationals with a strong resource base developed at the home country prior to international expansion. Large and well-established multinationals do not represent the majority of firms investing abroad, rather it is the smaller multinationals that are a part of this global landscape. These firms are using effective strategies of global integration (Mathews, 2006).

Correspondingly, the new OLI paradigm, proposed by Dunning (2000), admits that the growing importance of globalization and alliances highlighted knowledge creation as an incentive for global firms.

FDI can be approached, thereby, as a knowledge channel (Branstetter, 2006; Makino \& Inkpen, 2003). In fact, geographical localization facilitates new knowledge acquisition (Alcaer \& Chung, 2007). For this purpose, global firms oriented toward cross-border knowledge creation must leverage global coordination and local responsiveness (Stonehouse et al., 2007). Regarding the latter implication, valuable knowledge is generally tacit, and location-bound (Feinberg \& Gupta, 2004). This implies that subsidiaries incorporate local clusters and cooperate with performing organizations (Almeida \& Phene, 2004). Such an empowerment of subsidiary members denotes more sensitiveness and responsiveness regarding local stimuli (Bartlett \& Ghoshal, 2000). On that subject, Porter's diamond model summarizes the location stimuli that could support knowledge creation in a foreign location (Porter, 1990): 
(1) Demand sophistication: Hard-to-achieve local demand requirements spur domestic firms to raise their skill level;

(2) Local competition intensity: Firms operating in high-rivalry industries, commit more efforts in order to outperform the rest of competitors;

(3) Local firms commitment toward adopting relevant market strategies and organizational structures: Local firms would strive to apply these "best practices", in order to neutralize any competitor superiority;

(4) Presence of complex and developed inputs: The absence of natural and non-developed resources would encourage local firms to create their own inputs. If this tendency is sustained in time, local firms will be likely to build a specific pool of complex and developed inputs. The engagement in input creation efforts (which lies in frequently applying more efficient and effective inputs), will enable local firms to raise their knowledge base.

Hence, firms operating within a globalization setting are using FDI to take advantage of human capital differentials alongside production cost gaps (Buckley \& Ghauri, 2004). This entry mode is increasingly undertaken by SMEs (Kuo \& Li, 2003), especially those positioned in high-tech sectors (Fujita, 1995; Keeble, Lawson, Smith, Moore, \& Wilkinson, 1998). However, there are some difficulties that SMEs are faced with, i.e., bridging the cultural and the institutional distances between home and host countries (Knight, 2001; Lu \& Beamish, 2001) and overcoming the market entry barriers, related mostly to the need for specific information on customer preferences and key investments in technological assets (Beamish \& Lee, 2003). However, knowledge accumulation in foreign markets has been suggested as a supportive factor for global SMEs facing these difficulties (Anderson \& Boocock, 2002; Majocchi \& Zucchella, 2003). Global SMEs are continuously striving to enrich their stock of knowledge within market niches to distance themselves from competing with larger firms (Anderson et al., 2004; Audretsch, Prince, \& Thurik, 1999).

Knowledge is a set of principles, facts, skills, and rules. It underlies the organization's core competences (Stonehouse et al., 2007). Knowledge is stored in organizational procedures and norms (March, 1991). The process of knowledge creation consists of internally diffusing knowledge created by individuals and coordinating it with existing knowledge. More specifically, knowledge creation rests upon knowledge conversion, which lies in transforming tacit individual knowledge into explicit knowledge. Thus, tacit knowledge will become represented and explained (Nonaka \& von Krogh, 2009). On the one hand, "tacit knowledge covers knowledge that is unarticulated and tied to the senses, movement skills, physical experiences, intuition, or implicit rules of thumb” (Nonaka \& von Krogh, 2009, p. 635). On the other hand, explicit (or codified) knowledge is "uttered and captured in drawings and writing” (Nonaka \& von Krogh, 2009, p. 635).

Codifying tacit knowledge, i.e., making it more explicit, helps to articulate and to justify an individual's beliefs. Tacit knowledge and explicit knowledge are complementary. Advancing a firm's capacities consists of making appropriate combinations between new and existing tacit knowledge with new and existing explicit knowledge (Nonaka \& von Krogh, 2009). Moreover, knowledge creation is an interactive social practice, where members with different tacit knowledge backgrounds rally their efforts in order to upgrade their collective stock of knowledge. This could help individuals to overcome their bounded rationality and to extend their own knowledge. The outcome of knowledge conversion leads members of an organization to "reach an agreement on and provide a collective understanding of problems, solutions, tasks, and actions within the organization" (Nonaka \& von Krogh, 2009, p. 646). Given that it is based on information sharing and tight communication 
between actors, knowledge creation occurs within a learning environment inside the organization (Melton, Chen, \& Lin, 2006). In other words, knowledge is created by organizational learning (Lee, Chen, Kim, \& Johnson, 2008; March, 1991).

Organizational learning represents the dynamic mechanisms through which knowledge is created and shared in organizations (Kane \& Alavi, 2007). It is defined as "the dynamic process of creating new knowledge and transferring it to where it is needed and used, resulting in the creation of new knowledge for later transfer and use” (Kane \& Alavi, 2007, p. 796). "Learning is not random or blind, but directed. It consequently makes conceptual sense to say that human beings can act on behalf of organizations and also to argue that, on behalf of organizations, individuals can undertake experiential learning processes that yield behavioral outcomes that are reflected in organizational rules encoding the experiences concerned” (Holmqvist, 2004, p. 71). A learning process starts from an incident (e.g., crisis, a major client order) that is converted later into a new capability, based on information sharing that occurs between individuals, groups or organizations (Zhang, Macpherson, \& Jones, 2006). Therefore, organizational learning can help to rationalize organization actions, simplify experience, and delimit the temporal and spatial frame of action consequences (Levinthal \& March, 1993). New routines and methods are institutionalized as firm units reassess their existing practices in light of new insights gained from their global presence (Miesing, Kriger, \& Slough, 2007).

It has been acknowledged that two processes characterize organizational learning, i.e., exploitation and exploration (Bierly III et al., 2009; Holmqvist, 2004; Kane \& Alavi, 2007). More specifically, external knowledge is transferred to the organization first, and then applied in exploration and exploitation. This two-step process is referred to as the "absorptive capacity". Whereas exploration deals with generating new products and technologies, exploitation attempts to improve existing products and processes (Bierly III et al., 2009). "Exploration implies firm behaviors characterized by search, discovery, experimentation, risk taking and innovation, while exploitation implies firm behaviors characterized by refinement, implementation, efficiency, production and selection” (He \& Wong, 2004, p. 481). For this purpose, exploitation is centered on refining and elaborating the firm's experience. However, exploration is addressing the diversification of the experience through experimentation and free associations (Holmqvist, 2004). The extent of an exploration can be assessed through technological and market novelty for the firm, not for the industry as a whole (Greve, 2007).

Yet, exploration entails some risk taking, given that it intends to discover novel solutions (March, 1991). As a matter of fact, the returns of exploration are more remote in time (Greve, 2007), and less certain regarding useful related applications and best targeted receivers (March, 1991).

Both processes of exploitation and exploration apply to cross-border knowledge creation as well (Bartlett \& Ghoshal, 1989, 2000). Several authors acknowledge the growing presence of both types of assignments during globalization, i.e., existing specific-advantages exploitation and new specific-advantages exploration (Gassmann \& Keupp, 2007; Li \& Yue, 2005; Macpherson \& Holt, 2007). Exploitation and exploration assignments are devoted to upgrade the knowledge base of the global firm. The new interpretation of a global firm suggests that any local embedment should lead to the creation of new knowledge for the entire organization (Stonehouse et al., 2007). For those companies, globalization targets the local knowledge pool. Such an approach is qualified as a “transnational solution” (Bartlett \& Ghoshal, 1989, 2000). In the past, subsidiaries given exploitation assignments were not empowered to conceive new solutions for headquarters. Nevertheless, evidence shows that 
subsidiary assignments are evolving (Almeida \& Phene, 2004). Furthermore, exploitation could support cross-border knowledge creation, however at a slower pace than exploration (Chiesa, 1996; Li \& Yue, 2005). Adapting products to specific local needs upgrades the firm's knowledge pool (Miesing et al., 2007). Market closeness, enhanced by exploitation of home-country specific advantages, enables a certain augmentation of existing know-how (Chiesa, 1996). In fact, outcomes of exploitation lie in adapting to home-country developed products to the local market, which yields minor improvements on existing specific advantages. Exploration, however, allows for a more fundamental increase in a firm's knowledge base (Gassmann \& Keupp, 2007; Li \& Yue, 2005). Exploration mission consists in crossing new technological areas, in which the host country is relatively more advanced. This entails that a global firm browses local technological trends in order to capture what would be useful for the entire company (Chiesa, 1996). For this purpose, exploration subsidiaries are relatively less bound to the center's technology (Nobel \& Birkinshaw, 1998). They strive rather to capture local know-how and communicate it to the rest of the company (Singh, 2008).

Nevertheless, several scholars note that there is an interplay that should be managed in organizations between exploitation and exploration processes (He \& Wong, 2004; Holmqvist, 2004; Kane \& Alavi, 2007; Levinthal \& March, 1993; March, 1991). Given that they share a scarce amount of organizational resources, any excessive focus on one of these approaches can create tensions (He \& Wong, 2004). On the one hand, excessive exploration pitfalls are correlated to the lack of short-run returns. Exploration is favored when the organization is committed toward ongoing change and experimentation. However, such an engagement could sometimes be unrewarding, which can be risky when exploitation is overlooked (Levinthal \& March, 1993). On the other hand, obsolescence is a drawback of excessive exploitation. When an organization realizes high productive activities, it creates rapid rates of turnover. Thus, an organization could benefit from further exploitation of successful activities. This would drive out exploration into novel domains. Besides, the most common situation is when exploitation drives out exploration. In fact, learning processes are catalyzed by experience and therefore, organizations will tend to sustain exploiting their existing products because the related feedback is clearer, closer in time, and can be integrated rapidly (Levinthal \& March, 1993).

In hindsight, dissatisfaction is a key factor that permits organizational members to shift their learning processes toward more exploitation or more exploration. Dissatisfaction is resented when performance is under expectations. Furthermore, dissatisfaction along with exploitation can drive more exploration and vice versa (Holmqvist, 2004).

Dissatisfaction along with exploitation occurs from low performance. Thus, an organization would need to gather new experiences, sometimes from other organizations. Therefore, dissatisfaction with excessive intra-organizational exploitation leads to inter-organizational exploration to diversify experience. Excessive exploration can also yield dissatisfaction when few returns are collected and consequently, more focused experience is needed (Holmqvist, 2004). In summary, balancing between both learning processes ensures “current viability” through exploitation, as well as "future viability” via exploration (Levinthal \& March, 1993). According to Greve (2007), decoupling exploitation and exploration activities across subunits or over time can be an alternative to handle them.

Organizations making trade-offs between exploitation and exploration are qualified as ambidextrous organizations. These organizations are able to compete in mature markets where incremental innovation is 
needed, and to supply also emerging markets, where attention is turned to the search for new alternatives and products (He \& Wong, 2004).

Our intention in this manuscript is to investigate how global high-tech SMEs manage their FDI within a knowledge creation perspective. We chose to concentrate on high-tech SMEs because of their presence in competitive oligopolistic industries, in which they are constantly concerned by seeking new capabilities (Bell et al., 2003). For these reasons, our focus is two-fold: strategic and organizational. First, we propose to explore the strategic guidelines that could inform us on how global SME can balance exploitation and exploration in order to better perform cross-border knowledge-creation. Second, we will investigate the organizational practices that global high-tech SMEs can apply to accommodate the strategic trade-offs between exploitation and exploration processes. As a matter of fact, literature has shown that exploitation and exploration require different structures, strategies, cultures, processes, and capabilities (He \& Wong, 2004). Therefore, our propositions will attempt to capture the strategic choices as well as organizational practices applied by global high-tech SMEs in order to enhance cross-border knowledge-creation.

\section{Conceptual Framework}

The ever-increasing globalization of firms makes it necessary to understand how global small and medium-sized firms attain higher competitiveness in such context, given their shortage of resources. Knowledge has been the backbone for the globalization of SMEs. Acquiring worldwide knowledge allows "global SMEs" to foster their commitment toward foreign markets (Casillas et al., 2009). Thus, global high-tech SMEs could be concerned by developing their internal capacities from their direct presence in other countries. SMEs would invest in order to extend the exploitation of their home-based specific advantages and increase their sales. At the same time, they could show an interest to access local knowledge sources and to transform them into new capabilities through collaboration between all firm units. Generally speaking, an SME's strategic and organizational developments during the FDI stage represent the broader topic to be investigated in this paper. We will analyze the evolutionary globalization process of global high-tech SMEs from the perspective of knowledge creation.

A firm can gather new knowledge by spreading out its activities to foreign locations (Adenfelt \& Lagerstrom, 2006b). Offshore decentralization of knowledge creation activities is opposed to the centralized approach (Mendez, 2003), which is in conformity with the product life-cycle theory of Vernon (1966). Nowadays, decision making in global firms is considering the need to perform each activity in its corresponding optimal location (Buckley \& Ghauri, 2004).

Designing a global architecture of value-chain activities is important to develop new specific advantages abroad. This requires a global firm to determine the number of locations to host a given activity, with consideration given to the critical mass needed in order to achieve economies of scale. Moreover, a global firm has to choose the appropriate location for each activity. Designing an optimal global architecture consists of reducing duplications across locations for each activity performed. This global architecture has to be reassessed on a regular basis in order to accommodate for the changing environments in foreign countries (Gupta \& Govindarajan, 2001).

High-tech global SMEs are locally embedded, which means that they are more responsive to local market and develops location-bound specific advantages (Rugman \& Verbeke, 1992). The aforementioned diamond 
model of Porter (1990) informs on the local factors to which global firms can be responsive. Local embedment is linked, though, to the extent of the attributed assignment: exploitation or exploration (Macpherson \& Holt, 2007). Knowledge is created from performing learning activities during exploitation or exploration (March, 1991). The latter is associated to an increased local embedment (Kurokawa et al., 2007; Madambi \& Navarra, 2004; Nobel \& Birkinshaw, 1998). According to the transnational solution, any local embedment should lead to knowledge creation (Bartlett \& Ghoshal, 2000).

Moreover, some authors argue for a sequential relay between these two knowledge creation processes (Hedge \& Hicks, 2008; Kuemmerle, 1999). Globalization is usually done in a sequential manner: subsequent FDI flows into a given location are addressing different kinds of objectives than the initial introduction (Chang \& Rosenzweig, 2001). Most commonly, assignments evolve from exploitation to embrace exploration (Le Bas \& Sierra, 2002). Several researches noticed that the local market potential is the preliminary incentive for internationalizing firms. Afterwards, foreign firms will start showing more attention to other knowledge sources such as the location's specific capabilities (Frost \& Zhou, 2000; Hedge \& Hicks, 2008).

For global SMEs, the first introduction into the host country, on the one hand, would be motivated by developing existing knowledge throughout its adaptation to local market (i.e., exploitation). On the other hand, subsequent entries would focus on experiencing new knowledge fields (i.e., exploration). We should be aware of the aforementioned statement that an ambidextrous organization should not have any excessive concentration on one learning process at the expense of others (He \& Wong, 2004; Levinthal \& March, 1993). Thus, we believe that a certain balance between the two processes would be maintained in global SMEs.

When exploitation is favored, firms would be able to learn more about the host country setting, which represents a springboard before engaging in exploration. As a matter of fact, the latter assignment is associated to more critical challenges. Thus, the sequential relay between both assignments is needed to perform exploration (Kuemmerle, 1999). As a result, we assume that during its first introduction into a host country, a global SME would create knowledge by undertaking more exploitation activities. Afterwards, an SME would engage in more exploration activities. Such an assumption adheres to the evolutionary trend discussed in the Uppsala model of Johansson and Vahlne (1977).

Proposition 1: Global SME creates knowledge through more exploitation, before engaging in more exploration.

In Figure 1, the focus shift from exploitation to exploration is actually quite general at this level. We do not have knowledge about how this evolution will occur, whether gradually or drastically. Following this evolution, we do not know at which level global SMEs will arrive on the right side of the continuum. Will they commit a higher disproportional attention to exploration over exploitation, or will they be maintaining a more equilibrate balance between both activities? Obviously, if they move to the extreme right (left) of the continuum, we would assume that they show a deep commitment in exploration (exploitation). However, any excessive focus on either exploitation or exploration is an unfulfilling choice (He \& Wong, 2004; Levinthal \& March, 1993). Consequently, we expect that global SMEs will not overlook either exploitation or exploration. They will remain close to the equilibrium point on the graph. In other words, we believe that global SMEs will not position themselves on the extreme right. Such an initiative could be risky to their survival, given their lack of funds and knowledge. This exploitation-exploration evolution represents our strategy-related assumptions, 
regarding knowledge creation trade-offs in global SMEs. In summary, we suggest that a global SME would tend to engage more efforts in exploration as its FDI increases in a given location. The following propositions will deal with the organizational practices that will reflect this advocated strategic evolution.

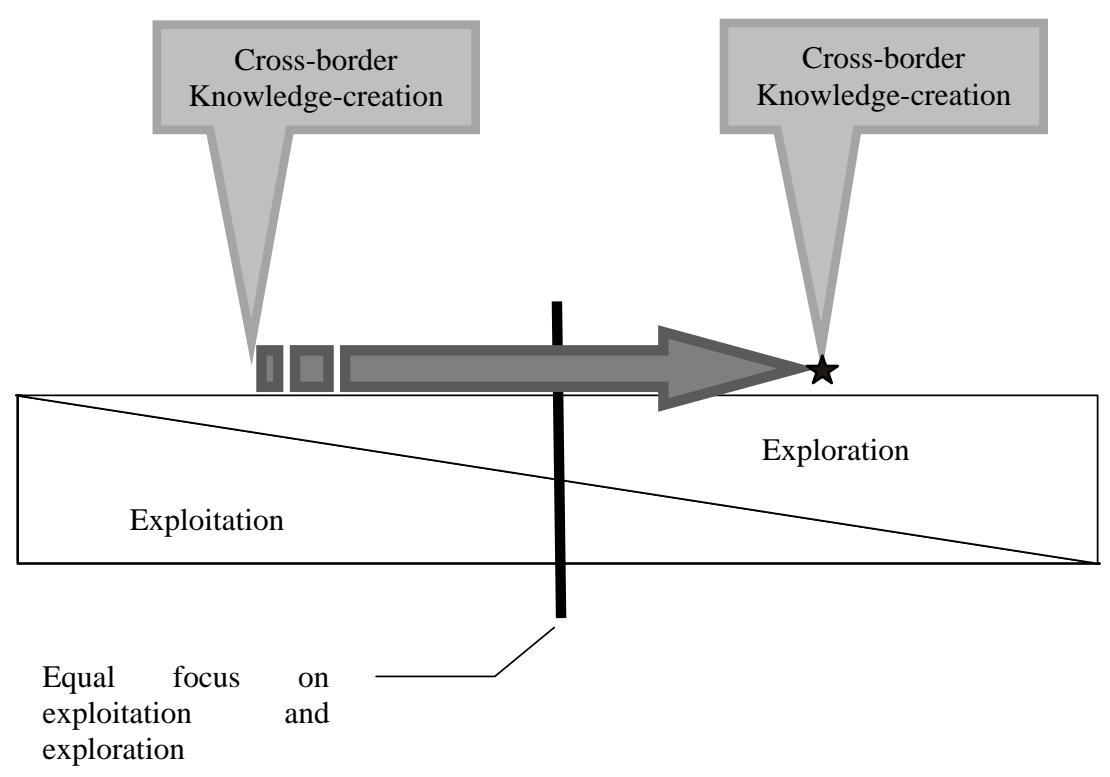

Figure 1. Global SME's evolution from more exploitation to more exploration during subsequent FDI.

The first organizational issue to be addressed in our propositions concerns how a global SME handles local knowledge sources, in accordance with the strategic move toward more exploration. Knowledge creation is performed by converting tacit into explicit knowledge (Nonaka \& von Krogh, 2009). In global SMEs, the search for new knowledge abroad is an iterative process based on appraisal of information relevance. Information on global markets can be sourced either from internal or external sources (Casillas et al., 2009). Internally, tacit knowledge is acquired through action and daily practice (Nonaka \& von Krogh, 2009). Global firms can also source knowledge assets from external actors (Dunning, 2000). The social capital consisting in vertical relationships with large foreign customers is a prominent source of knowledge for start-ups abroad (Presutti, Boari, \& Fratocchi, 2007). Furthermore, global SMEs can establish partnerships with suppliers (Yeoh, 1994), and within local scientific communities (Autio, Kanninem, \& Gustafsson, 2008; von Zedtwitz, 2004). Evidence shows that exploration is better supplied from partnerships established with universities and public R\&D centers. Such scientific partners provide academic knowledge, which is hard to source otherwise. Academic knowledge underpins the reinvention of existing capabilities (Van Beers, Berghall, \& Poot, 2008). We would then expect that global SMEs to engage in more cooperation with universities and public R\&D centers in the host country, when exploration becomes the predominant part in knowledge creation. On the other side of the spectrum, exploitation needs applied knowledge to become more available to suppliers and customers. Applied knowledge is more helpful when it comes to market trends and specific customer needs (Van Beers et al., 2008).

Proposition 2: Global SME cooperates more with local customers and suppliers, as it performs more exploitation than exploration. 
Proposition 3: Global SME cooperates more with local universities and public R\&D centers, as it performs more exploration than exploitation.

Transforming multi-domestic knowledge into new products relies not only on transferring it, but also on appropriate integration effort (Subramaniam, 2006). Synergies, stimulated by internal knowledge integration, enable the development of new specific advantages (Singh, 2008). Knowledge integration is the ending phase of knowledge creation process in global SMEs. Three stages are identified within this process, i.e., the possession of previous knowledge, the decision to search new knowledge and the absorption and combination of new knowledge with existing knowledge (Casillas et al., 2009). In short, knowledge is effectively created during this integration phase. The tacit knowledge gathered during exploitation and/or exploration is converted into new specific advantages through internal interdependence of all business units. Therefore, it is important to understand how decentralized units communicate together in order to convert the tacit knowledge they gather locally into explicit knowledge. The following propositions will attempt to grasp the organizational choices that global SMEs can make in order to facilitate internal communication and on the whole, to convert knowledge into new specific advantages.

Global knowledge integration relies on the capacity of the headquarters to absorb the knowledge generated by subsidiaries (Birkinshaw, Hood, \& Jonsson, 1998). For this purpose, it is important to develop formal as well as informal organizational routines that will guide the transmission of knowledge between all firm units (Feinberg \& Gupta, 2004). In other words, global knowledge integration needs the presence of a well-definite organizational structure (Lipparini \& Fratocchi, 1999). In this regard, Adenfelt and Lagerstrom (2006a) identified two possible organizational structures that support cross-border knowledge integration: multi-domestic and independent. The former consists in empowering several subsidiaries, from different locations, to work on the same assignment. These subsidiaries will rally and manage their forces in order to attain the assigned goal. The multi-domestic structure exists for a predetermined period of time, where knowledge is created collectively in several sites. Once developed, each plant will apply this knowledge locally, according to the idiosyncrasy of its environment. The independent structure, on the other side, refers to the designation of a single subsidiary to take in charge the whole innovation process. This independent structure implies that subsidiaries are more autonomous during knowledge development process. They can define more independently their future technological orientations, in an emergent way, without being bound to other plants. The knowledge outcome, locally and independently developed in each site, is shared afterward with the rest of the firm (Adenfelt \& Lagerstrom, 2006a).

The independent structure has been advocated for highly strategic tasks. In fact, when firm members are asked to explore new specific advantages, more interaction will be needed in order to enhance tacit knowledge communication (Gassmann \& von Zedtwitz, 2003). Bearing this in mind, we endorse the same assumption for global SMEs. When a global SME favors exploration over exploitation, it will likely benefit from the independent mode given its intention to experiment in new knowledge domains.

Proposition 4: Global SME applies a multi-domestic structure, as it performs more exploitation than exploration.

Proposition 5: Global SME applies an independent configuration, as it performs more exploration than exploitation. 


\section{Conclusion}

Cross-border knowledge creation in global SMEs has been discussed as a crucial topic (Casillas et al., 2009). Our stage-assumptions are dealing with this evidence. They reflect the strategic as well as the organizational choices that a global high-tech SME would make in order to achieve knowledge creation goals through exploitation and exploration. In previous studies, FDI utilization was a matter of increasing control over existing specific advantages, exploiting market imperfections and attenuating risks related to an agent's opportunism (Rugman \& Verbeke, 1992). The product lifecycle theory, developed first by Vernon (1966), was underpinning this transaction cost apprehension of FDI flows. According to this conception, knowledge creation is bound to the home country (Almeida, Song, \& Grant, 2002). Later on, theoretical developments started pointing out the usefulness of developing host country-bound specific advantages (Chen, Chen, \& Ku, 2004; Rugman \& Verbeke, 1992). Furthermore, FDI aiming at knowledge creation was not discussed enough in literature (Frost \& Zhou, 2000). The shortcoming of the transaction cost theory with respect to the FDI explanation lies in its incapacity to underline cross-border knowledge-creation as a fundamental issue in a global SME's survival. Thus, our paper extends the Uppsala model using a new avenue in the OLI model, traditionally dominated by the transaction cost interpretation. However, even though some critics were directed toward the adequacy of the Uppsala process with respect to high-tech SMEs and especially those called "Born global SMEs", we believe that our assumptions can reveal how these SMEs manage their direct presence in foreign markets. Scholars claim that born global SMEs do not stick to the evolutionary stage process, i.e., once they are created, they engage in international activities (Compagno, Pittino, \& Visintin, 2005; Crick \& Spence, 2005). A large portion of born global SMEs operate in technology-intensive sectors (Bell, Crick, \& Young, 2004). To explain this idiosyncratic aspect, authors advance the usefulness of the entrepreneur's social capital in gathering valuable know-how about the international marketplace. The bonds established with other organizations have significant influence on the internationalization speed of these SMEs (Coviello \& Munro, 1997).

Other theoretical contribution can be assessed in this paper. Our contribution to the OLI model consists of analyzing market-seeking FDI and strategic asset-seeking FDI from the same perspective, i.e., knowledge creation. As a matter of fact, Dunning (2000) did not consider that the exploitation of home-based specific advantages on the global marketplace could be a knowledge source. Moreover, we assume the presence of a potential relay between both objectives for global SMEs. Knowledge creation will be accelerated in the presence of valuable knowledge sources. From this evolving perspective, we point out our principal theoretical contribution with respect to the Uppsala stage model. We assume that a global SME would start creating knowledge by undertaking more exploitative activities than exploration activities. A global SME needs to fully exploit its home-based specific advantages in the host country. The returns of exploitation are rapid and more certain. Thus, a global SME can rapidly offset the costs engaged in FDI. Exploration is supposed to be privileged, then, if the host country environment is wealthy in terms of valuable sources of knowledge. Further, we argue that such a strategic evolution toward more exploration should be followed by some organizational steps, i.e., partner selection, IDE mode, integration channels. However, our manuscript contains some shortcomings. First, SMEs are reputed to have a clear core business. Thus, it could be unconceivable to some of them to experiment in distant technological fields. These global SMEs could maintain more focus on exploitation 
during subsequent FDI. Thus, they could stay positioned on the left side of the continuum. Consequently, it will be promising to carry an empirical study in order to determine whether global SMEs can illustrate different knowledge creation trends on the exploitation-exploration continuum, depending on specific features. Furthermore, Dunning (2000) advocates the presence of three sorts of objectives in FDI, i.e., cost economies, market growth, and knowledge creation. Our propositions did not inform on how cost objectives interfere with knowledge creation and sales issues. Of course, we do not advocate the exclusion of transaction cost validity in the diagnosis of global SMEs. We believe that transaction cost theory is still valid in analyzing global SMEs. Chen and $\mathrm{Hu}$ (2002) notice that the transaction cost analysis is necessary to make sure that the intended entry mode will lead to the upper performance. However, Madhok (1998) stipulates that firms must give consideration to entry modes that yield more knowledge flows to the firm, despite transaction cost disadvantages. As a result, global SMEs could balance exploitation and exploration activities differently, according to the established priorities. Further studies are needed in order to grasp if cost concern determines the importance a global SME gives to cross-border knowledge creation and the evolution that results from the choice made.

\section{References}

Adenfelt, M., \& Lagerstrom, K. (2006a). Knowledge development and sharing in multinational corporations: The case of a centre of excellence and a transnational team. International Business Review, 15, 381-400.

Adenfelt, M., \& Lagerstrom, K. (2006b). Enabling knowledge creation and sharing in transnational projects. International Journal of Project Management, 24, 191-198.

Alcaer, J., \& Chung, W. (2007). Location strategies and knowledge spillovers. Management Science, 53(5), 760-776.

Almeida, P., \& Phene, A. (2004). Subsidiaries and knowledge creation: The influence of the MNC and host country on innovation. Strategic Management Journal, 25, 847-864.

Almeida, P., Song, J., \& Grant, R. M. (2002). Are firms superior to alliances and markets? An empirical test of cross-border knowledge building. Organization Science, 13(2), 147-161.

Anderson, V., \& Boocock, G. (2002). Small firms and internationalisation: learning to manage and managing to learn. Human Resource Management Journal, 12(3), 5-25.

Audretsch, D., Prince, Y., \& Thurik, R. (1999). Do small firms compete with large firms. Atlantic Economic Journal, 27(2), 201-209.

Autio, E., Kanninem, S., \& Gustafsson, R. (2008). First-and second-order additionality and learning outcomes in collaborative R\&D programs. Research Policy, 37, 59-76.

Bartlett, C. A., \& Ghoshal, S. (1989). Managing across borders: The transnational solution. Boston: Harvard Business School Press.

Bartlett, C. A., \& Ghoshal, S. (2000). Transnational management. McGraw-Hill.

Beamish, P. W., \& Lee, C. (2003). The characteristics and performance of affiliates of small and medium-size multinational enterprises in an emerging market. Journal of International Entrepreneurship, 1, 121-134.

Bell, J., Crick, D., \& Young, S. (2004). Small firm internationalization and business strategy: An exploratory study of knowledge-intensive and traditional manufacturing firms in the UK. International Small Business Journal, 22(1), 23-56.

Bell, J., McNaughton, R., Young, S., \& Crick, D. (2003). Toward an integrative model of small firm internationalization. Journal of International Entrepreneurship, 1(4), 339-362.

Bierly III, P. E., Damanpour, F., \& Santoro, M. D. (2009). The application of external knowledge: Organizational conditions for exploration and exploitation. Journal of Management Studies, 46(3), 481-509.

Birkinshaw, J., Hood, N., \& Jonsson, S. (1998). Building firm-specific advantages in multinational corporations: The role of subsidiary initiative. Strategic Management Journal, 19, 221-141.

Branstetter, L. (2006). Is foreign direct investment a channel of knowledge spillovers? Evidence from Japan’s FDI in the Unites States. Journal of International Economics, 68, 325-344.

Buckley, P. J., \& Ghauri, P. N. (2004). Globalization, economic geography and the strategy of multinational enterprises. Journal of International Business Studies, 35, 81-98. 
Casillas, J. C., Moreno, A. M., Acedo, F. J., Gallego, M. A., \& Ramos, E. (2009). An integrative model of the role of knowledge in the internationalization process. Journal of World Business, 44, 311-322.

Chang, S. J., \& Rosenzweig, P. M. (2001). The choice of entry mode in sequential foreign direct investment. Strategic Management Journal, 22(8), 747-776.

Chen, H., \& Hu, M. Y. (2002). An analysis of determinants of entry mode and its impact on performance. International Business Review, 11(2), 193-210.

Chen, H., Chen, T. J., \& Ku, Y. H. (2004). Foreign direct investment and local linkages. Journal of International Business Studies, 35(4), 320-334.

Chen, R., \& Martin, M. (2001). Foreign expansion of small firms: The impact of domestic alternatives and prior foreign business involvement. Journal of Business Venturing, 16, 557-574.

Chiesa, V. 1996. Managing the internationalization of R\&D activities. Engineering Management, 43(1), 7-23.

Compagno, C., Pittino, D., \& Visintin, F. (2005). Corporate governance and advanced forms of internationalisation in Italian SMEs. International Journal of Globalisation and Small Business, 1(2), 168-182.

Coviello, N. E., \& Munro, H. J. (1997). Network relationships and the internationalization process of small software firms. International Business Review, 6(40), 361-86.

Crick, D., \& Spence, M. (2005). The internationalisation of "high performing” UK high-tech SMEs: A study of planned and unplanned strategies. International Business Review, 14, 167-185.

Dunning, J. H. (1977). Trade, location of economic activity and the MNE: A search for an eclectic approach. In B. Ohlin, P. O. Hesselborn, \& P. M. Wijkman (Eds.), The international allocation of economic activity. Macmillan, London, 395-418.

Dunning, J. H. (2000). The eclectic paradigm as an envelope for economic and business theories of MNE activity. International Business Review, 9(2), 163-190.

Feinberg, S. E., \& Gupta, A. K. (2004). Knowledge spillovers and the assignment of R\&D responsibilities to foreign subsidiaries. Strategic Management Journal, 25, 823-845.

Frost, T., \& Zhou, C. (2000). The geography of foreign R\&D within a host country: An evolutionary perspective on location-technology selection by multinationals. International Studies of Management and Organization, 30(2), 10-43.

Fujita, M. (1995). Small and medium-sized transnational corporations: Trends and patterns of foreign direct investment. Small Business Economics, 7, 183-204.

Gassmann, O., \& Keupp, M. M. (2007). The internationalization of research and development in Swiss and German born Globals: Survey and case study evidence. International Journal of Entrepreneurship and Small Business, 4(3), 214-233.

Greve, H. R. (2007). Exploration and exploitation in product innovation. Industrial and Corporate Change, Advance Access published May 26, 1-31.

Gupta, A. K., \& Govindarajan, V. (2000). Knowledge flows within multinational corporations. Strategic Management Journal, 21(4), 473-496.

He, Z. L., \& Wong, P. K. (2004). Exploration vs. exploitation: An empirical test of the ambidexterity hypothesis. Organization Science, 15(4), 481-494.

Hedge, D., \& Hicks, D. (2008). The maturation of global corporate R\&D: Evidence from the activity of US foreign subsidiaries. Research Policy, 37, 390-406.

Holmqvist, M. (2004). Experiential learning processes of exploitation and exploration within and between organizations: An empirical study of product development. Organization Science, 5(1), 70-81.

Johanson, J., \& Vahlne, J. E. (1977). The internationalisation process of the firm. Journal of International Business Studies, 8, 23-32.

Kane, G. C., \& Alavi, M. (2007). Information technology and organizational learning: An investigation of exploration and exploitation processes. Organization Science, 18(5), 796-812.

Keeble, D., Lawson, C., Smith, H. L., Moore, B., \& Wilkinson, F. (1998). Internationalisation process, networking and local embeddness in technology-intensive small firms. Small Business Economics, 11, 327-342.

Knight, G. A. (2001). Entrepreneurship and strategy in the international SME. Journal of international management, 7(3), 155-171.

Kuemmerle, W. (1999). Foreign direct investment in industrial research in the pharmaceutical and electronics industries—Results from a survey of multinational firms. Research Policy, 28(2-3), 179-193.

Kuo, H. C., \& Li, Y. (2003). A dynamic decision model of SMEs’ FDI. Small Business Economics, 20, 219-231.

Kurokawa, S., Iwata, S., \& Roberts, E. B. (2007). Global R\&D activities of Japanese MNCs in the US: A triangulation approach. Research Policy, 36, 3-36. 
Le Bas, C., \& Sierra, C. (2002). Location versus home country advantages' in R\&D activities: Some further results on multinationals' locational strategies. Research Policy, 31, 589-609.

Lee, R. P., Chen, Q., Kim, D., \& Johnson, J. L. (2008). Knowledge transfer between multinational corporations’ Headquarters and their subsidiaries: Influences on and implications for new product outcomes. Journal of International Marketing, 16(2), 1-31.

Levinthal, D. A., \& March, J. G. (1993). The myopia of learning. Strategic Management Journal, 14, 95-112.

Li, J., \& Yue, D. R. (2005). Managing global research and development in China: Patterns of R\&D configuration and evolution. Technology Analysis \& Strategic Management, 17(3), 317-338.

Lipparini, A., \& Fratocchi, L. (1999). The capabilities of the transnational firm: Accessing knowledge and leveraging inter-firm relationships. The European Management Journal, 17(6), 655-667.

Lu, J. W., \& Beamish, P. W. (2001). The internationalization and performance of SMEs. Strategic Management Journal, 22(6), 565-586.

Macpherson, A., \& Holt, R. (2007). Knowledge, learning and small firm growth: A systematic review of the evidence. Research Policy, 36, 172-192.

Madhok, A. (1998). The nature of multinational firm boundaries: Transaction costs, firm capabilities and foreign market entry mode. International Business Review, 7(3), 259-290.

Majocchi, A., \& Zucchella, A. (2003). Internationalization and performance: Findings from a set of Italian SMEs. International Small Business Journal, 21(3), 249-268.

Makino, S., Lau, C. M., \& Yeh, R. S. (2002). Asset-exploitation versus asset-seeking: Implications for location choice of foreign direct investment from newly industrialized economies. Journal of International Business Studies, 33(3), 403-421.

March, J. G. (1991). Exploration and exploitation in organizational learning. Organization Science, 2(1), 71-87.

Mathews, J. A. (2006). Dragon multinationals: New players in 21st century globalization. Asia Pacific Journal of Management, 23(1), 5-27.

Melton, C. E., Chen, J. C. H., \& Lin, B. (2006). Organizational knowledge and learning: Leveraging it to accelerate the creation of competitive advantages. International Journal of Innovation and Learning, 3(3), 254-266.

Mendez, A. (2003). The coordination of globalized R\&D activities through project teams organization: an exploratory empirical study. Journal of World Business, 38, 96-109.

Miesing, P., Kriger, M. P., \& Slough, N. (2007). Towards a model of effective knowledge transfer within transnationals: The case of Chinese foreign invested enterprises. The Journal of Technology Transfer, 32, 109-122.

Mudambi, R., Mudambi, S. M., \& Navarra, P. (2007). Global innovation in MNCs: The effects of subsidiary self-determination and teamwork. The Journal of Product Innovation Management, 24, 442-455.

Nonaka, I., \& von Krogh, G. (2009). Tacit knowledge and knowledge conversion: Controversy and advancement in organizational knowledge creation theory. Organization Science, 20(3), 635-652.

Porter, M. E. (1990). The competitive advantage of nations. Macmillan: London

Presutti, M., Boari, C., \& Fratocchi, L. (2007). Knowledge acquisition and the foreign development of high-tech start-ups: A social capital approach. International Business Review, 16(1), 23-46.

Rugman, A. M., \& Verbeke, A. (1992). A note on the transnational solution and the transaction cost theory of multinational strategic management. Journal of International Business Studies, 23(4), 761-771.

Singh, J. (2008). Distributed R\&D, cross-regional knowledge integration and quality of innovative output. Research Policy, 37, 77-96.

Stonehouse, G., Campbell, D., Hamill, J., \& Purdie, T. (2007). Global and transnational business: Strategy and management (2nd ed.). Wiley-India: New Delhi.

Subramaniam, M. (2006). Integrating cross-border knowledge for transnational new product development. Journal of Product Innovation Management, 23, 541-555.

Van Beers, C., Berghall, E., \& Poot, T. (2008). R\&D internationalization, R\&D collaboration and public knowledge institutions in small economies: Evidence from Finland and Netherlands. Research Policy, 37, 294-308.

Vernon, R. (1966). International investment and international trade in the product life cycle. Quarterly Journal of Economics, 80, 190-207.

Von Zedtwitz, M. (2004). Managing foreign R\&D laboratories in China. R\&D Management, 34(4), 439-452.

Yeoh, P. L. (2004). International learning: Antecedents and performance implications among newly internationalizing companies in an exporting context. International Marketing Review, 21(4/5), 511-535.

Zhang, M., Macpherson, A., \& Jones, O. (2006). Conceptualizing the learning process in SMEs: Improving innovation through external orientation. International Small Business Journal, 24(3), 299-323. 